\title{
Registry Studies Use Inconsistent Methods to Account for Patients Lost to Follow-up, and Rates of Patients LTFU Are High
}

\author{
Kalyan Vamshi Vemulapalli, B.Sc., \\ Karadi Hari Sunil Kumar, M.B.B.S., M.Ch. Ortho., F.E.B.O.T., F.R.C.S.Ed. (Tr. \& Orth.), and \\ Vikas Khanduja, M.A. (Cantab), M.Sc., F.R.C.S. (Tr. \& Orth.), Ph.D.
}

\begin{abstract}
Purpose: To determine methods described in the literature to account for patients lost to follow-up (LTFU) in registry studies and whether rates of patient LTFU are within acceptable margins. Methods: A scoping review, where a literature search is conducted for studies from 9 arthroscopy registries, was performed on EMBASE, MEDLINE, and the annual reports of each registry. Inclusion criteria included studies with information on patient-reported outcome measures and being based on 9 national registries identified. Exclusion criteria included review articles, conference abstracts, studies not based on registry data, and studies from regional, claims-based, or multicenter registries. Studies were then divided into categories based on method of LTFU analysis used. Results: Thirty-six articles were identified for the final analysis. Categories for LTFU analysis included dropout analyses $(n=10)$, referencing validation studies $(n=12)$, contacting nonresponders $(n=4)$, and sensitivity analyses $(n=1)$. Referencing validation studies was the most common method $(\mathrm{n}=12)$. Majority $(\mathrm{n}=35)$ of the studies exceeded the recommended maximum rates for LTFU. Conclusions: Registry studies use inconsistent methods to account for patient LTFU, and rates of patients LTFU are unacceptably high. Clinical Relevance: The impact of patients LTFU in studies related to arthroscopic intervention is unknown. A universal method for accounting for patient follow-up is needed.
\end{abstract}

$\mathbf{R}$ ecent advances over the last 2 decades have led to rapid progress in surgical techniques and innovation in implant technology. However, along with these advances there is a constant need to monitor the outcome of these surgical techniques and newer implants to ensure that adverse outcomes are identified early and intervened upon in the best interest of the patients.

From the Medical Student, Imperial College School of Medicine (K.V.V.), London; Specialty Registrar, Addenbrooke's-Cambridge University Hospital (K.H.S.K.), Cambridge, and Cambridge Young Adult Hip Service (V.K.), Addenbrooke's-Cambridge University Hospital, Cambridge, UK.

The authors report the following potential conflicts of interest or sources of funding: V.K. is an educational consultant for Smith $\theta$ nephew and Arthrex. Full ICMJE author disclosure forms are available for this article online, as supplementary material.

Received April 2, 2021; accepted July 24, 2021

Address correspondence to Vikas Khanduja, M.A. (Cantab), M.Sc., F.R.C.S. (Tr. $\theta$ Orth.), Ph.D., Cambridge Young Adult Hip Service, Addenbrooke's-Cambridge University Hospital, Box 37, Hills Road, Cambridge CB20QQ,UK.E-mail:vk279@cam.ac.uk

(C) 2021 THE AUTHORS. Published by Elsevier Inc. on behalf of the Arthroscopy Association of North America. This is an open access article under the CC BY-NC-ND license (http://creativecommons.org/licenses/by-nc-nd/4.0/). 2666-061X/21431

https://doi.org/10.1016/j.asmr.2021.07.016
The establishment of registries such as the Swedish Knee and Hip Arthroplasty registries (in 1977 and 1979, respectively), ${ }^{1,2}$ the United Kingdom National Joint Registry in $2002^{3}$ are methods used to achieve this level of monitoring. Registries are also useful in providing a good platform for research because of their low cost, large observational datasets, and the ease of analyzing data in comparison with other research methodologies. Outcome based registries in particular contain information on diagnosis, details of procedures, patientreported outcome measures (PROMs), and long-term follow-up of patients. After the establishment of arthroplasty registries worldwide, arthroscopy registries have also been developed.

Many such registries use PROMs in the form of a standardized questionnaire to quantify various aspects of health including pain, quality of life, and function of the joint after the procedure. PROMs are collected at multiple time points in the follow-up of patients. Unfortunately, the rates of completion of PROMs or other surveys are often low because of poor response rates or patients "lost to follow-up" (LTFU). ${ }^{4}$ This means that studies based on these PROMs can be 
influenced by nonresponse bias if the patients lost to follow-up are nonrandom or "missing not at random." ${ }^{5}$

Despite this, many studies assume their missing data is "missing at random" and subsequently assume no nonresponse bias because there is no systematic reason for patients being LTFU. ${ }^{5}$ As a result, there is a possibility that these studies may overestimate the success of the interventions they are investigating. To avoid nonresponse bias, studies may incorporate missing data analysis to justify the validity of their data and results. Some methods for these "loss to follow-up analyses" include carrying out a comparison of baseline characteristics of patients, ${ }^{6,7}$ referencing a validation study ${ }^{8,9}$ that has been carried out on the registry or contacting nonresponders themselves. ${ }^{10,11}$

However, there is no universal agreement on the methodology to be used to account for LTFU nor on the acceptable follow-up rates for studies reported from arthroscopy registries. Traditionally, an $80 \%$ follow-up is seen as an acceptable compliance threshold for a survey study to be valid, which has been attributed to Sackett at al. ${ }^{12}$ by other studies. ${ }^{13,14}$ However, this number was chosen arbitrarily, and there was no statistical basis for it. Alternatively, the International Society of Arthroplasty Registries PROMs Working Group has recommended a minimum follow-up rate of $60 \% .{ }^{15}$ This cutoff is also recommended by the Journal of the American Medical Association for survey-based research. ${ }^{16}$

The purposes of this study were to determine methods described in the literature to account for patients LTFU in registry studies and whether rates of patient LTFU are within acceptable margins. We hypothesized that the rates of patient LTFU would be within the acceptable margins for survey studies and that there are methods used by authors to account for LTFU.

\section{Methods}

This scoping review was carried out using the methods outlined by Arksey and $\mathrm{O}^{\prime}$ Malley ${ }^{17}$ to determine statistical methods used to account for and minimize the impact of patients LTFU.

\section{Search strategy}

A computer-based literature search of EMBASE, Medline, and a manual search of the latest annual reports of each arthroscopy registry was conducted on October 22, 2020. The eligibility criteria for the included articles were determined a priori by the authors. Inclusion criteria were that studies were from the PROM collecting arthroscopy registries as outlined by Ueland et al. ${ }^{14}$ and that the studies performed or referenced some form of LTFU analysis based either on their patient pool or on the patients in the registry the studies were based on. Studies were excluded if they did not meet these inclusion criteria, were conference abstracts or reviews, or did not have publication available in the English language.

The search strategy (Supplementary Table S1) consisted of the names of each of the included registries, (including variations of the names such as abbreviations), followed by a manual search of papers from the annual report of that registry. For example, to search for articles from the Swedish National Knee Ligament Registry (SNKLR), the search terms were "Swedish National Knee Ligament Regist*," "Swedish Knee Ligament Regist*," "Swedish National Anterior Cruciate Ligament Regist*," "Swedish Anterior Cruciate Ligament Regist*," "SNKLR," "SKLR." This was then followed up by a manual search of the 2019 annual report (latest report) of the SNKLR for additional studies.

A list of the registries included in the search are shown in Table 1. Further details on these registries can be found in Supplementary Table S2. One author carried out the search strategy, and article screening was performed by 2 authors, with any disagreements resolved by the senior author.

From the literature search, a screening was performed first of the titles and then of the abstracts. Following this, articles were selected for full-text review prior to final analysis. The references for each of the studies selected for final analysis were then scanned to identify any further relevant studies. A PRISMA (preferred reporting items for systematic reviews and metaanalyses) flowchart of the literature search is shown in Fig 1.

Variables included for articles that met the inclusion criteria were the size of patient sample, percentage of patients LTFU, type of LTFU analysis performed, and the registry the study was based on. The registry annual reports that were not available in English were translated using Google Translate. The extracted data were collated in Microsoft Excel. Statistical analyses focused on descriptive statistics.

\section{Results}

In total, 283 studies were identified in the original database search with an additional 173 studies included from the manual search of annual reports. After the removal of duplicates, 233 records were identified for

Table 1. List of Registries Included in the Literature Search

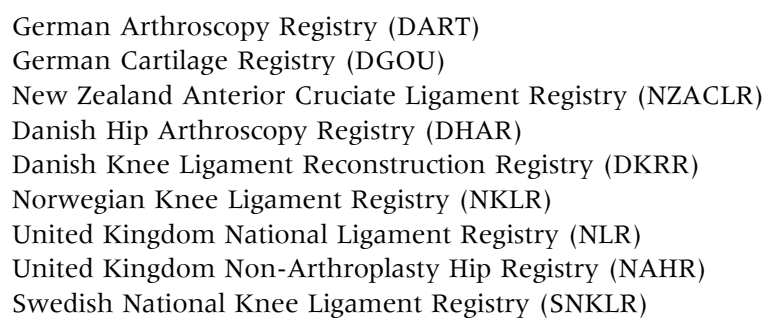


Fig 1. PRISMA (preferred reporting items for systematic reviews and meta-analyses) chart outlining studies returned during the literature search.

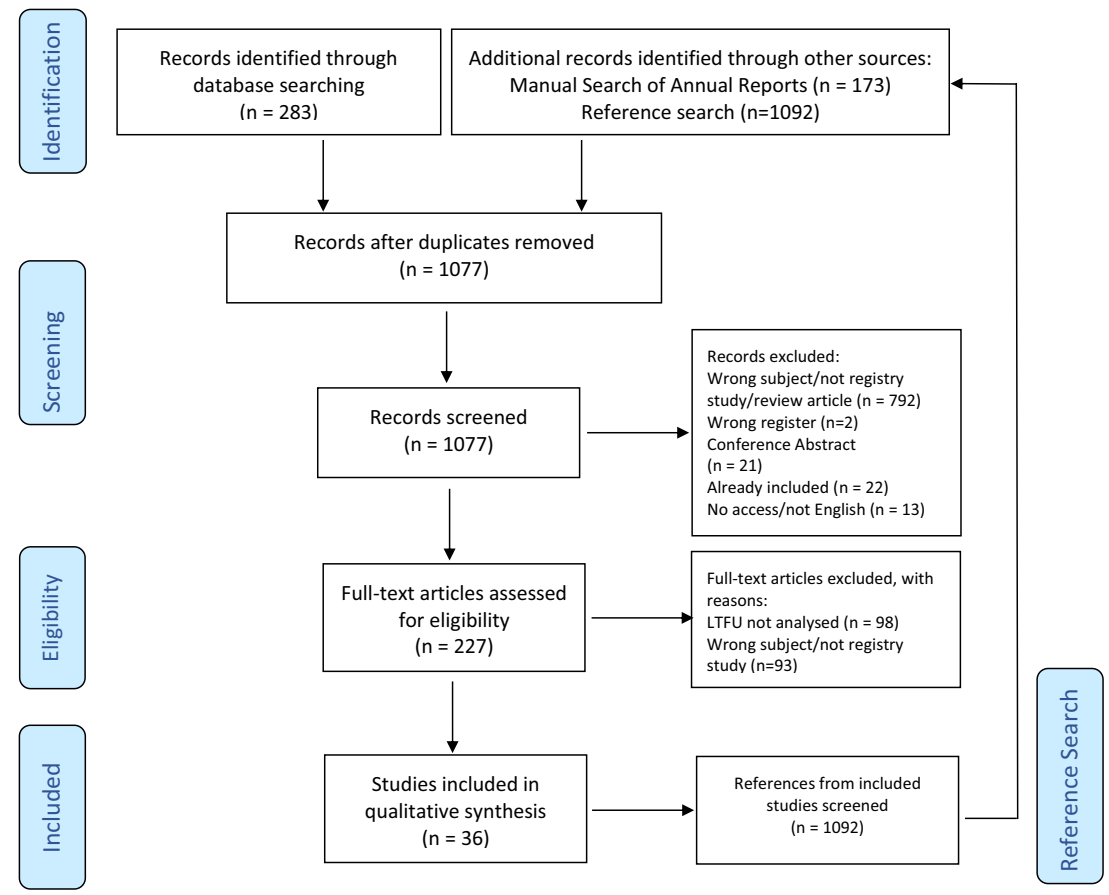

the screening of titles and abstracts. Following this, 157 texts were identified for full-text analysis, resulting in 36 studies included for final analysis. One thousand ninety-two references from bibliographies of the included studies were then screened, leading to 70 further full-text articles being assessed. However, none of these additional 70 studies met the inclusion criteria, suggesting the search strategy was strong enough to capture all the required articles.

Included studies were divided into 5 categories (Table 2) depending on the type of LTFU analysis that was carried out. The main themes identified in the articles to account for loss to follow-up were (1) dropout analysis, (2) reference of a validation study, (3) contacting nonresponders, and (4) sensitivity analysis. No papers from the DGOU, DART, or NZACLR met the inclusion criteria to be eligible for this review. The reported rates of LTFU from each study was also noted.
The details of the included studies, including the reported rates of LTFU, are summarized in Table 3. Following this, the maximum and minimum reported LTFU rates from the studies from each of the registries were compared to determine whether data from any 1 registry met any of the recognized follow-up percentage guidelines. These values are presented in Table 4 .

\section{LTFU Analysis among the registries}

From the 36 included articles, 5 categories of LTFU analyses were derived.

\section{Dropout analysis}

Dropout analyses were one of the most common methods of LTFU analysis with 10 studies reporting on this. This involved comparison of the baseline demographic details (e.g., age and sex) between patients who completed the PROMs and those who did not. The

Table 2. Categories of LTFU analyses Into Which the 36 Included Studies Were Divided

\begin{tabular}{|c|c|c|c|}
\hline $\bar{l}$ & Dropout analysis & $\begin{array}{l}\text { Compared the baseline characteristics of } \\
\text { responders and nonresponders }\end{array}$ & 10 \\
\hline 2 & Referenced validation study & $\begin{array}{l}\text { Used a validation study on the respective } \\
\text { registry to validate the quality of data }\end{array}$ & 12 \\
\hline 1,2 & $\begin{array}{l}\text { Both Dropout analysis and } \\
\text { reference to a validation study }\end{array}$ & & 3 \\
\hline 3 & Contacted nonresponders & Contacted nonresponders for missing data & 4 \\
\hline
\end{tabular}

LTFU, lost to follow-up. 


\begin{tabular}{|c|c|c|c|c|c|c|c|}
\hline Publication & Registry & $\mathrm{N}$ & $\begin{array}{c}\text { Subject } \\
\text { Characteristics } \\
\end{array}$ & PROMS & Significant Non-Responder Factors & $\begin{array}{l}\text { Publication Noncompliance } \\
\text { (\% of Patients LTFU) (\%) }\end{array}$ & Category \\
\hline$\overline{\text { Poulsen et al. }}{ }^{6}$ & DHAR & 2886 & $\begin{array}{l}\text { All registry } \\
\text { patients }\end{array}$ & $\begin{array}{c}\text { HAGOS, iHOT12, EQ-5D-3L, } \\
\text { VAS, HSAS }\end{array}$ & Male, younger age & l year: 42 & 1 \\
\hline Lind et al. ${ }^{26}$ & DKRR & 25,281 & ACLR, MCLR & $\begin{array}{c}\text { KOOS, } \\
\text { Tegner Activity }\end{array}$ & & $\begin{array}{l}\text { Pre-op: } 67 \\
\text { l year: } 82\end{array}$ & 2 \\
\hline Eysturoy et al. ${ }^{27}$ & DKRR & 17,204 & ACLR & $\begin{array}{l}\text { KOOS, } \\
\text { Tegner Activity }\end{array}$ & & $\begin{array}{l}\text { Pre-op: } 67 \\
\text { Post-op :78 }\end{array}$ & 2 \\
\hline Nissen et al. ${ }^{30}$ & DKRR & 1619 & ACLR & $\begin{array}{c}\text { KOOS, } \\
\text { Tegner Activity }\end{array}$ & & 1 year: 73 & 2 \\
\hline Lind et al. ${ }^{31}$ & DKRR & 22,401 & ACLR, PCLR & $\begin{array}{l}\text { KOOS, } \\
\text { Tegner Activity }\end{array}$ & & $\begin{array}{l}\text { Pre-op: } 65 \\
\text { l year: } 73\end{array}$ & 2 \\
\hline Bjerre et al. ${ }^{40}$ & DKRR & & ACLR & $\begin{array}{l}\text { KOOS, } \\
\text { Tegner Activity }\end{array}$ & $\begin{array}{l}\text { Not invited to follow-up, data not } \\
\text { sent to DKRR }\end{array}$ & 1 year: 41 & 5 \\
\hline Fauno et al. ${ }^{32}$ & DKRR & 14,806 & ACLR & $\begin{array}{l}\text { KOOS, } \\
\text { Tegner Activity }\end{array}$ & & $\begin{array}{l}\text { Pre-op: } 61 \\
\text { l year: } 74\end{array}$ & 2 \\
\hline Rahr-Wagner et al. ${ }^{33}$ & DKRR & 13,647 & ACLR & $\begin{array}{l}\text { KOOS, } \\
\text { Tegner Activity }\end{array}$ & & $\begin{array}{l}\text { Pre-op: } 61 \\
1 \text { year: } 74\end{array}$ & 2 \\
\hline Rahr-Wagner et al. ${ }^{34}$ & DKRR & 8375 & & $\begin{array}{c}\text { KOOS, } \\
\text { Tegner Activity }\end{array}$ & & $\begin{array}{l}\text { Pre-op: } 63 \\
1 \text { year: } 69\end{array}$ & 2 \\
\hline Rahr-Wagner et al. ${ }^{9}$ & DKRR & 14,500 & ACLR & $\begin{array}{l}\text { KOOS, } \\
\text { Tegner Activity }\end{array}$ & $\begin{array}{c}\text { Male, younger age, ACLR non- } \\
\text { revision }\end{array}$ & $\begin{array}{l}\text { Pre-op } 67 \\
1 \text { year: } 73\end{array}$ & 3 \\
\hline Lind et al. ${ }^{10}$ & DKRR & 12,193 & ACLR & KOOS & & $\begin{array}{l}\text { Pre-op: } 61 \\
1 \text { year: } 72\end{array}$ & 3 \\
\hline Sandon et al. ${ }^{35}$ & SNKLR & 684 & Soccer players & EQ-5D, KOOS & & & 2 \\
\hline Kraus et al. ${ }^{36}$ & SNKLR & 26,014 & ACLR & EQ-5D, KOOS & & 2 year: $\sim 50 \%$ & 2 \\
\hline Balasingam et al. ${ }^{7}$ & SNKLR & 2229 & & KOOS & Male, younger age & $\begin{array}{c}\text { Pre-op: } 44 \\
5 \text { year: } 53 \\
10 \text { year: } 63\end{array}$ & 1,2 \\
\hline Hamrin Senorski et al. ${ }^{18}$ & SNKLR & 874 & ACLR & KOOS & $\begin{array}{c}\text { Male, younger age, articular injury, } \\
\text { meniscal injury }\end{array}$ & 10 year: 59 & 1 \\
\hline Hamrin Senorski et al. ${ }^{58}$ & SNKLR & 272 & ACLR & Tegner Activity & & 1 year: 39 & 1 \\
\hline Hamrin Senorski et al. ${ }^{59}$ & SNKLR & 263 & ACLR & Tegner Activity & & 1 year: 51 & 1 \\
\hline Hamrin Senorski et al. ${ }^{37}$ & SNKLR & 6889 & $\begin{array}{l}\text { Single bundle } \\
\text { ACLR with } \\
\text { hamstring } \\
\text { tendons }\end{array}$ & KOOS & & 2 year: 55 & 2 \\
\hline Hamrin Senorski et al. ${ }^{42}$ & SNKLR & 343 & ACL & KOOS & & & 5 \\
\hline Reinholdsson et al. ${ }^{8}$ & SNKLR & 1723 & ACL surgery & EQ-5D, KOOS & $\begin{array}{l}\text { Male, younger age, worse KOOS } \\
\text { pain, worse KOOS quality of life }\end{array}$ & 2 year: 48 & 3 \\
\hline Samuelsson et al. ${ }^{28}$ & SNKLR & 23,952 & ACLR & KOOS & & $\begin{array}{l}1 \text { year: } 70 \\
2 \text { year: } 70\end{array}$ & 2 \\
\hline Hamrin Senorski et al. ${ }^{29}$ & SNKLR & 13,636 & $\begin{array}{l}\text { Single bundle } \\
\text { ACLR }\end{array}$ & KOOS & & $\begin{array}{l}\text { Pre-op: } 31 \\
1 \text { year: } 47 \\
2 \text { year: } 55\end{array}$ & 2 \\
\hline Barenius et al. ${ }^{44}$ & SNKLR & 8584 & ACLR & KOOS & Male & 2 year: 59 & 5 \\
\hline
\end{tabular}

(1)




\begin{tabular}{|c|c|c|c|c|c|c|c|}
\hline Publication & Registry & $\mathrm{N}$ & $\begin{array}{c}\text { Subject } \\
\text { Characteristics }\end{array}$ & PROMS & Significant Non-Responder Factors & $\begin{array}{l}\text { Publication Noncompliance } \\
\text { (\% of Patients LTFU) }(\%)\end{array}$ & Category \\
\hline Ahlden et al. ${ }^{45}$ & SNKLR & 16,351 & ACLR & KOOS & & $\begin{array}{l}\text { Pre-op: } 36 \\
1 \text { year: } 42 \\
2 \text { year: } 51 \\
5 \text { year: } 60\end{array}$ & 5 \\
\hline Ageberg et al. ${ }^{41}$ & SNKLR & 10,164 & ACLR & $\begin{array}{l}\text { EQ-5D, } \\
\text { KOOS }\end{array}$ & & $\begin{array}{l}\text { Pre-Op: } 48-56 \\
1 \text { year: } 62-63 \\
2 \text { year: } 76-79\end{array}$ & 5 \\
\hline Ulstein et al. ${ }^{19}$ & SNKLR \& NKLR & 8470 & ACLR & KOOS & Male, younger & 5 year: 46 & 1,2 \\
\hline Ulstein et al. ${ }^{20}$ & SNKLR \& NKLR & 368 & ACLR & KOOS & $\begin{array}{c}\text { Male, younger, shorter time from } \\
\text { injury to ACLR }\end{array}$ & $\begin{array}{l}\text { Pre-op: } 24 \\
5 \text { year: } 43 \text { ( } 5 \text { year figure is } \\
\text { the percentage of patients } \\
\text { who had pre-op KOOS) }\end{array}$ & 1,2 \\
\hline Rotterud et al. $^{21}$ & SNKLR \& NKLR & 357 & $\begin{array}{l}\text { ACLR and } \\
\text { concomitant } \\
\text { full-thickness } \\
\text { cartilage lesion }\end{array}$ & KOOS & $\begin{array}{c}\text { Male, younger, shorter time from } \\
\text { injury to ACLR }\end{array}$ & $\begin{array}{l}\text { Pre-op: } 25 \\
\text { 2-year: } 45 \text { (2 year figure is } \\
\text { the percentage of patients } \\
\text { who had pre-op KOOS) }\end{array}$ & 1 \\
\hline Rotterud et al. ${ }^{22}$ & SNKLR \& NKLR & 8476 & ACLR & KOOS & Male, younger age & 2 year: 46 & 1 \\
\hline Owesen et al. ${ }^{23}$ & NKLR & 252 & PCLR & KOOS & Male, younger age & 2 year: 32 & 1 \\
\hline Owesen et al. ${ }^{60}$ & NKLR & 5237 & PCLR, ACLR & KOOS & Male & $\begin{array}{l}2 \text { year: } 47 \\
\text { PCL: } 35 \\
\text { ACL } 44\end{array}$ & 1 \\
\hline LaPrade et al. ${ }^{24}$ & NKLR & 4691 & ACLR & KOOS & Male, younger age & 2 year: 37 & 1 \\
\hline Grindem et al. ${ }^{43}$ & NKLR & 2690 & ACLR & KOOS & & 2 year: 53 & 5 \\
\hline Granan et al..$^{25}$ & NKLR & 5517 & ACLR & KOOS & Male, younger, more ACLR revisions & 2 year: 36 & 1 \\
\hline Holleyman et al. ${ }^{38}$ & NAHR & 630 & $\begin{array}{l}\text { Periacetabular } \\
\text { osteotomy for } \\
\text { DDH or FAI }\end{array}$ & EQ-5D, iHOT12 & Younger age & $\begin{array}{l}\text { iHOT-12: } \\
\text { Pre-op: } 10 \\
6 \text { month: } 48 \\
12 \text { month: } 47 \\
2 \text { year: } 85 \\
\text { EQ-5D: } \\
\text { Pre-op: } 8 \\
6 \text { month: } 47 \\
12 \text { month: } 46 \\
2 \text { year: } 79\end{array}$ & 4 \\
\hline Maempel et al. ${ }^{11}$ & NAHR & 88 & FAI & EQ-5D, іHOT12 & & 1 year ${ }^{\dagger}: 19$ & 3 \\
\hline
\end{tabular}

DHAR, Danish Hip Arthroscopy Registry; DKRR, Danish Knee Ligament Reconstruction Registry; NKLR, Norwegian Knee Ligament Registry; NLR, United Kingdom National Ligamen Registry; NAHR, United Kingdom Non-Arthroplasty Hip Registry; SNKLR, Swedish National Knee Ligament Registry; ACLR, anterior cruciate ligament reconstruction; MCLR, medial cruciate ligament reconstruction; PCLR, posterior cruciate ligament reconstruction; DDH, developmental dysplasia of the hip; FAI, femoroacetabular impingement; HAGOS, Copenhagen Hip and Groin Outcome Score; iHOT12, 12 item International Hip Outcome Tool; EQ-5D-3L, EuroQol-5D-3L; EQ-5D, EuroQol-5D; VAS, visual analog scale; HSAS, Hip Sports Activity Scale; KOOS, Knee Injury and Osteoarthritis Outcome Score.

Some studies referenced a validation study, but unless they were referencing a validation study on the register that the study itself is based on, they did not meet criteria for category 2 and thus did not meet the inclusion criteria.

${ }^{\dagger}$ Patients were contacted by survey if they did not reply to the 1-year follow-up survey. The median response time was 24.3 months 
Table 4. The Maximum and Minimum Compliance Percentages (if Present) of Patient Follow-Up for the Studies That Met the Inclusion Criteria From Each Registry

\begin{tabular}{|c|c|c|}
\hline Registry & $\begin{array}{l}\text { LTFU Percentage for Study } \\
\text { with the Highest LTFU } \\
\text { (Lowest Compliance) \% }\end{array}$ & $\begin{array}{c}\text { LTFU Percentage for } \\
\text { Study with } \\
\text { the Lowest LTFU } \\
\text { (Highest Compliance) \% }\end{array}$ \\
\hline$\overline{\text { DHAR }}$ & 1 year: 42 & 1 year: 42 \\
\hline DKRR & $\begin{array}{l}\text { Pre-op: } 67 \\
\quad 1 \text { year: } 82\end{array}$ & $\begin{array}{l}\text { Pre-op: } 61 \\
\quad \text { l year: } 41\end{array}$ \\
\hline SNKLR & $\begin{array}{l}\text { Pre-op: } 48-56 \\
\text { 1 year: } 62-63 \\
2 \text { year: } 76-79 \\
10 \text { year: } 63\end{array}$ & $\begin{array}{l}\text { Pre-op: } 31 \\
1 \text { year: } 39 \\
2 \text { year: } 48 \\
10 \text { year: } 59\end{array}$ \\
\hline NKLR & 2 year: 53 & 2 year: 32 \\
\hline NAHR & 1 year: 47 & 1 year: $19^{\dagger}$ \\
\hline
\end{tabular}

LTFU, lost to follow-up; DHAR, Danish Hip Arthroscopy Registry; DKRR, Danish Knee Ligament Reconstruction Registry; SNKLR, Swedish National Knee Ligament Registry; NKLR, Norwegian Knee Ligament Registry; NAHR, United Kingdom Non-Arthroplasty Hip Registry; NLR, United Kingdom National Ligament Registry; DGOU, German Cartilage Registry.

Multiple $(>1)$ studies must have a follow-up percentage at a certain time point for that time point to be included in the table above. Studies were included only if reporting on a single registry and those that were based on multiple registries are not included in this table. No studies from the NLR or the DGOU were eligible for inclusion and therefore are not included in the table.

* Only one study met the eligibility criteria from the DHAR, therefore the highest and lowest compliance is the same

${ }^{\dagger}$ Patients were contacted by survey if they did not reply to the 1-year follow-up survey. The median response time was 24.3 months

most common finding was that nonresponders tended to be of male sex and younger age. ${ }^{6,7,18-27}$ However, some studies found worse outcomes in nonresponders such as having more ACLR revisions. ${ }^{25}$

\section{Referencing a validation study}

Twelve papers ${ }^{28-39}$ referenced a validation study only, and an additional 3 articles $^{7,19,20}$ referenced both a validation study and carried out a dropout analysis. Two validation studies were carried out on the dataset of 2 registries: the SNKLR and DKRR. These studies evaluated the completeness and the quality of the data in their respective registries to determine whether reliable conclusions could be drawn from them. This also included identifying whether there were any differences in demographic details or PROMs between responders and nonresponders in the registry.

Rahr-Wagner et al. ${ }^{9}$ carried out a validation study on the DKRR. The authors sent out 100 questionnaires to a sample of both, responders and nonresponders. Comparisons were then drawn between the responses from these. It was found that nonresponders tended to be male and of a younger age. For the SNKLR, a similar strategy was used by Reinholdsson et al. ${ }^{8}$ where all nonresponders $(\mathrm{n}=1723)$ were contacted, of which $349(21 \%)$ replied. Again, it was found that nonresponders tended to be male and younger, but they also tended to have a higher level of pain and lower quality of life.

\section{Contacting Nonresponders}

Four studies contacted nonresponders to increase the follow-up compliance percentage in their study. Lind et al. ${ }^{10}$ contacted 200 responders and 200 nonresponders, out of which $60 \%$ replied and showed that there was no difference in the Knee Injury and Osteoarthritis Outcome Score (KOOS) scores at the 1-year follow-up between the 2 groups. Maempel et al. ${ }^{11}$ attempted to contact each nonresponder a maximum of 5 times, after which they were able to increase their compliance to $81 \%$ (LTFU of $19 \%$ ). The aforementioned validation studies by Reinholdsson et al. ${ }^{8}$ and Rahr-Wagner et al. ${ }^{9}$ are also included in this category.

\section{Sensitivity Analysis}

From the included studies, Holleyman et al. ${ }^{38}$ conducted a different sensitivity analysis to adjust for differences in demographics between responders and nonresponders. This was carried out by creating a cohort ("overall cohort") with bootstrapping (random sampling with replacement) responders and nonresponders, followed by creating another cohort ("responder cohort") via the same process of random sampling from all of the responders. Next, randomly selected responders from the "overall cohort" were transferred into the "responder cohort" and removed from the "overall cohort." Nearest neighbor matching was used to match cases from the remaining patients in the bootstrapped overall cohort to those in the responder cohort based on age, sex, body mass index, and surgical diagnosis. This was repeated 1000 times. This did not aim to find differences between patients who were and were not LTFU but aimed to mitigate the bias that may have arisen as a result of the differences. Rahr-Wagner et al. ${ }^{39}$ also mention a sensitivity analysis very briefly but do not display the data or the methodology behind it and therefore is not included in this category.

\section{Other}

This category was formed of studies that did not meet the descriptions of the other categories but still performed some form of LTFU analysis. Of the six studies in this category, one was based on the DKRR and 5 on the SNKLR. The study from the DKRR looked at reasons for LTFU by focusing on the administrative failures of several hospitals when sending data to the DKRR. ${ }^{40}$ From the 5 studies from the SNKLR, 1 only looked at differences in response rates between male and female sexes $^{41}$ and 4 stated that there were no differences between responders and nonresponders (suggesting a dropout analysis was performed) while not providing data as evidence for this. ${ }^{42-45}$ 


\section{Discussion}

The main findings of this study were that there was no consistent method used to account for LTFU in arthroscopy registry studies. Many studies did not have any methods to account for loss to follow-up, and from those that did, there disagreement on how to tackle it and minimal acknowledgment of the potential bias it can introduce.

Despite a number of arthroscopic outcome studies acknowledging patients being LTFU as a limitation of their work, only 36 studies included some variant of a LTFU analysis in our review. Amongst these studies, there was no consensus on which was the best method of accounting for LTFU. The use of dropout analyses $(n=10)$, using validation studies $(n=12)$, or a mix of both $(\mathrm{n}=3)$ were the most commonly used, whereas only 1 study used a sensitivity analysis.

\section{Dropout analysis}

Dropout analyses have the advantage of allowing a direct comparison of demographic details between patients who are lost to follow-up and those who are not. With such data, information on the likelihood of a patient from a particular demographic background (sex, age, preoperative clinical picture, and PROM scoring) can be used to predict whether the patient will be LTFU. From this, patients who at a higher risk of being nonresponders can then be focused upon with additional procedures of making contact such as trying to organize a phone call to ask them to be followed up, rather than an email.

\section{Referencing a validation study}

Both validation studies found that were only minimal differences in PROMs between responders and nonresponders. For the validation study on the DKRR, only $62 \%(62 / 100)$ of responders and 32\% (32/100) of nonresponders replied to the questionnaire. Since only 32 participants represented the entire cohort of nonresponders from the registry, it would be incorrect to conclude whether factors did or did not differ between responders and nonresponders in the DKRR. ${ }^{9}$ For the validation study on the SNKLR, despite all nonresponders being contacted for follow-up, only $21 \%$ $(359 / 1723)$ of nonresponders responded to the additional questionnaire. Because the majority of nonresponders still did not provide reasons for being LTFU or return their PROMs, there may have been other differences between the nonresponder and responder group in terms of outcomes and PROMs. ${ }^{8}$ The low response rate from nonresponders in both of these studies suggests that the noncompliance was not due to chance but due to an underlying reason. Significant factors for nonresponders included male sex and a younger in age in both studies. An increased level of pain and worse quality of life KOOS score in nonresponders was noted by Reinholdsson et al. ${ }^{8}$ Only 2 studies $^{7,28}$ of the 8 from the SNKLR that refenced the validation studies acknowledged the difference in these KOOS scores. The other studies from the SNKLR and the DKRR had simple statements stating there were no significant differences between responders and nonresponders.

Many studies refer to these to validate their dataset despite failing to recognize the limitations of these two studies. However, without a higher sample size for both studies, it may be disingenuous to make this assertion.

\section{Contacting Nonresponders}

Contacting nonresponders has the advantage of increasing the sample size of the study data, and therefore limiting the effects of nonresponse bias that may have otherwise been present. However, not all nonresponders reply, meaning that there may still be elements of nonresponse bias. Additionally, nonresponders may be contacted at a date many months after the 1-year or 2-year follow-up timelines, and so there may either be missing data for the time points where there is no response, or there may be recall bias where these patients do not give accurate responses on how they were feeling at the time. For example, if a complication arose after when the l-year follow-up time would have been, but the patient responded after being contacted at a later date, the data may bias the 1-year follow-up data.

\section{Sensitivity Analysis}

Sensitivity analyses play roles in the assessment of how robust the conclusions drawn from the primary analysis of data are by examining how the results are affected by changes in methods, models, assumptions, or missing data. When data are missing, the options of sensitivity analysis include either analyzing only complete cases (assume data is missing completely at random) or impute the missing data using imputation methods and redoing the analysis. Most studies should assume that data is missing not at random. There are several single and multiple imputation methods that can be chosen depending on the type of data being collected and depending on whether it is missing at random. ${ }^{46}$

Just as it is common in clinical trials, it is of our opinion that all registry studies should incorporate a sensitivity analysis to mitigate the effects of nonresponse bias. However, only 1 study of the 36 included studies performed a sensitivity analysis.

As previously mentioned, the accepted rate of LTFU is disputed for survey studies, ranging from $20 \%$ to $40 \%$. Only 1 study $^{11}$ achieved a LTFU rate of less than $20 \%$. Several studies quoted LTFU rates of greater than $50 \%$, with 1 study from DKRR quoted a LTFU as high as $82 \%$ at 1 year. ${ }^{26}$ Although the recommended compliance 
rates differ between different guidelines, none of them quote a value of LTFU as high as seen in many of the included studies.

A simulation study by Kristman et al. ${ }^{5}$ observed that even follow-up rates of $80 \%$ (LTFU rate of $20 \%$ ) were associated with a considerable bias if data were missing not at random. Zelle et al. ${ }^{13}$ further performed a simulation study to assess for an acceptable percentage of responders. The study was performed on a polytrauma database from which patient data was deleted randomly at an increasing percentage to simulate various levels of LTFU. It was found that in the 50 simulations performed, only nonresponder rates of $15 \%$ or less had no changes in significance on their studied outcome. On the other hand, a nonresponder rate of $20 \%$ changed significance in 14 of the 50 simulations they ran on the database.

There are other methods described to alleviate or account for LTFU in arthroscopy studies from the nonregistry studies. One recent example includes the incorporation of machine learning into arthroscopy patient databases where the system can predict the patients that are most likely to not-respond. The study by Kunze et al. ${ }^{47}$ looked at 27 different preoperative variables including patient characteristics (such as age, sex, body mass index, race), patient behaviors (such as smoking, alcohol intake, drug use), orthopaedic history (such as previous surgery) and at PROMs to develop 3 models, each of which revealed patients most likely to be LTFU. The 3 models used were "cross-validation," minimizing "Bayes information criteria," and "adaptive selection." Common variables that predicted LTFU among the 3 models were when patients who were of the male sex, nonwhite, smokers, not providing telephone numbers, and having a greater preoperative modified Harris Hip score and international Hip Outcome Tool 12-component questionnaire score (PROMs).

There are also varied conclusions on whether patients LTFU have different outcomes compared to those that are followed-up. An epidemiological study by Ekholm et al. ${ }^{48}$ suggested a positive correlation between socioeconomic status and response rates of patients to health interview surveys, although the authors did note there was no significant association between health and nonresponsiveness in their study. Furthermore, a validation study on a local registry was carried out by Lindman et al. ${ }^{49}$ reported a larger percentage of replies by nonresponders (76\% out of 140 nonresponders) than the validation studies included in this review. Their study found that there was no significant difference in patient-reported hip function according to the PROMs carried out after hip arthroscopy. However, patients who were nonresponders were more likely to be less satisfied with their treatment, younger, and male sex. However, the authors noted that other studies on orthopaedic LTFU analysis did not find significant differences in satisfaction with treatment $t^{50,51}$ and that studies on nonresponders after arthroplasty procedures reported worse outcomes in terms of knee function in nonresponders. ${ }^{52,53}$

A consensus must be reached regarding the handling of missing data and accounting for LTFU of patients included in arthroscopy registries. Because of the compliance rate of arthroscopy registries being lower than those of arthroplasty registries, these issues (despite being of importance) are less pressing for those registries. Although most studies use a dropout analysis or a reference to a validation study, there may be other methods that are more robust in alleviating for nonresponse bias. A follow-up rate of more than $85 \%$ may be needed to overcome effects of LTFU and have robust outcome data from registries.

The best form of minimizing nonresponse bias in a registry-based study is to avoid missing data; however, this is not always possible. Possible explanations for poor data collection may include length of questionnaires, method of contacting patients, patients not taking part in follow up due to their outcomes, or patient demographic factors. From the studies included (Table 3), common demographic factors for patients who are LTFU is that they are of male sex and often younger, and therefore more appropriate contact methods (other than questionnaires sent by post or email) may be beneficial. The SNKLR Annual Report from $2019^{54}$ states that new data collection methods such as mobile applications or social media should be explored. The annual report also explores the idea of shortening the length of questionnaires to minimize the time needed to answer each questionnaire. The KOOS questionnaire for the knee for example contains 42 items in 5 sections, whereas the iHOT- 12 only contains 12 items as it is a shortened version of the much longer iHOT-33 (a 33 item questionnaire). ${ }^{55,56}$ Finally, as arthroscopy is a minimally invasive surgery it has shorter recovery times and fewer complications (such as infection $)^{57}$ meaning patients may not feel the need to attend follow-up appointments or answer questionnaires in the years after the procedure.

As well as minimizing missing data, another possible next step after this review could be to perform a consensus study using experts in the field of registries to both determine an acceptable percentage of follow-up compliance and also to determine a universal method for accounting for patient LTFU. Guidelines may be formed from this consensus to guide future arthroscopy registry-based research.

\section{Limitations}

There are some limitations to this study. Firstly, only studies from PROM collecting national registries were included in the analysis. Studies from registries that are 
not nationally centralized may have had other forms of statistical analysis that are used to alleviate for patients who are LTFU. Examples of these include the Multicenter Orthopaedic Outcomes Network and the Kaiser Permanente Anterior Cruciate Ligament Reconstruction Registry, both of which have had numerous studies carried out using data from their patient cohorts. However, studies from such registries were not considered in the search for this review as they do not represent national arthroscopy registries. Second, annual reports for the DKRR and DGOU registries were not available in the English language and had to be translated by Google translate. Native speakers and readers of the languages (Danish and German) were not consulted for the accuracy of the translation. This meant that there was a reliance on the translation software to provide accurate translations. Finally, the search for LTFU analysis was limited to arthroscopy registries, which are still relatively new compared to the arthroplasty registries. However, we are not aware of any consensus on what LTFU analysis method should be used in arthroplasty registries, but this is not as great a concern because the rates of LTFU are lower in arthroplasty registries. ${ }^{14}$

\section{Conclusions}

Registry studies use inconsistent methods to account for patient LTFU, and rates of patients LTFU are unacceptable.

\section{References}

1. Svenska Höftprotesregistret (Swedish Hip Arthroplasty Register). About the Register. https://shpr. registercentrum.se/in-english/about-the-register/p/ BJGov4yrz.

2. The Swedish Knee Arthroplasty Register. http://myknee. se/en/.

3. National Joint Registry. About the NJR. https://www. njrcentre.org.uk/njrcentre/About-the-NJR.

4. Johnson TP, Wislar JS. Response Rates and Nonresponse Errors in Surveys. JAMA 2012;307:1805-1806.

5. Kristman V, Manno M, Côté P. Loss to follow-up in cohort studies: How much is too much? Eur J Epidemiol 2003;19: 751-760.

6. Poulsen E, Lund B. The Danish Hip Arthroscopy Registry: Registration completeness and patient characteristics between responders and non-responders. Clin Epidemiol 2020;12:825-833.

7. Balasingam S, Sernert N, Magnusson H. Patients with concomitant intra-articular lesions at index surgery deteriorate in their knee injury and osteoarthritis outcome score in the long term more than patients with isolated anterior cruciate ligament rupture: A study from the Swedish National Anterior Cruciate Ligament Register. Arthroscopy 2018;34:1520-1529.

8. Reinholdsson J, Kraus-Schmitz J, Forssblad M, Edman G, Byttner M, Stalman A. A non-response analysis of 2-year data in the Swedish Knee Ligament Register. Knee Surg Sports Traumatol Arthrosc 2017;25:2481-2487.

9. Rahr-Wagner L, Thillemann TM, Lind MC. Validation of 14,500 operated knees registered in the danish knee ligament reconstruction register: Registration completeness and validity of key variables. Clin Epidemiol 2013;5: 219-228

10. Lind M, Menhert F, Pedersen AB. Incidence and outcome after revision anterior cruciate ligament reconstruction: Results from the Danish registry for knee ligament reconstructions. Am J Sports Med 2012;40:1551-1557.

11. Maempel JF, Ting JZ, Gaston P. Assessing the outcome of hip arthroscopy for labral tears in femoroacetabular impingement using the minimum dataset of the British Non-arthroplasty Hip Register: A single-surgeon experience. Arthroscopy 2018;34:2131-2139.

12. Sackett DL. Evidence-Based Medicine: How to Practice and Teach EBM. New York: Churchill Livingstone, 1997.

13. Zelle BA, Bhandari M, Sanchez AI, Probst C, Pape H-C. Loss of follow-up in orthopaedic trauma. J Orthop Trauma 2013;27:177-181.

14. Ueland TE, Carreira DS, Martin RL. Substantial loss to follow-up and missing data in national arthroscopy registries: A systematic review. Arthroscopy 2021;37:761-770. e3.

15. Rolfson O, Bohm E, Franklin P, et al. Patient-reported outcome measures in arthroplasty registries. Acta Orthop 2016;87:9-23 (Suppl 1).

16. JAMA. Instructions for Authors. https://jamanetwork. com/journals/jama/pages/instructions-for-authors.

17. Arksey H, O'Malley L. Scoping studies: Towards a methodological framework. Int J Soc Res Methodol 2005;8:19-32.

18. Hamrin Senorski E, Svantesson E, Spindler KP, AlentornGeli E, Westin O, Karlsson J. Ten-year risk factors for inferior knee injury and osteoarthritis outcome score after anterior cruciate ligament reconstruction: A study of 874 patients from the Swedish National Knee Ligament Register. Am J Sports Med 2018;46:2851-2858.

19. Ulstein S, Aroen A, Engebretsen L, Forssblad M, Lygre SHL. Effect of concomitant cartilage lesions on patient-reported outcomes after anterior cruciate ligament reconstruction: A nationwide cohort study from Norway and Sweden of 8470 patients with 5-year followup. Orthop J Sport Med 2018;6(7):2325967118786219.

20. Ulstein S, Aroen A, Engebretsen L, Forssblad M, Lygre SHL. A controlled comparison of microfracture, debridement, and no treatment of concomitant fullthickness cartilage lesions in anterior cruciate ligamentreconstructed knees: A nationwide prospective cohort study from Norway and Sweden of 368 patients with 5year follow-up. Orthop J Sport Med 2018;6(8): 2325967118787767.

21. Rotterud JH, Sivertsen EA, Forssblad M, Engebretsen L. Effect on patient-reported outcomes of debridement or microfracture of concomitant full-thickness cartilage lesions in anterior cruciate ligament-reconstructed knees: A nationwide cohort study from Norway and Sweden of 357 patients with 2-year follow-up. Am J Sports Med 2016;44: 337-344.

22. Rotterud JH, Sivertsen EA, Forssblad M, Engebretsen L. Effect of meniscal and focal cartilage lesions on patient- 
reported outcome after anterior cruciate ligament reconstruction: A nationwide cohort study from Norway and Sweden of 8476 patients with 2-year follow-up. Am J Sports Med 2013;41:535-543.

23. Owesen C, Rotterud JH, Engebretsen L. Effect of activity at time of injury and concomitant ligament injuries on patient-reported outcome after posterior cruciate ligament reconstruction. Orthop J Sport Med 2018;6(12): 2325967118817297.

24. LaPrade CM, Dornan GJ, Granan LP, LaPrade RF. Outcomes after anterior cruciate ligament reconstruction using the Norwegian Knee Ligament Registry of 4691 patients: How does meniscal repair or resection affect short-term outcomes? Am J Sports Med 2015;43: 1591-1597.

25. Granan LP, Baste V, Engebretsen L. Associations between inadequate knee function detected by KOOS and prospective graft failure in an anterior cruciate ligamentreconstructed knee. Knee Surg Sports Traumatol Arthrose 2015;23:1135-1140.

26. Lind M, Jacobsen K, Nielsen T. Medial collateral ligament (MCL) reconstruction results in improved medial stability: Results from the Danish knee ligament reconstruction registry (DKRR). Knee Surg Sports Traumatol Arthrosc 2020;28:881-887.

27. Eysturoy NH, Nielsen TG. Anteromedial portal drilling yielded better survivorship of anterior cruciate ligament reconstructions when comparing recent versus early surgeries with this technique. Arthroscopy 2019;35:182-189.

28. Samuelsson K, Magnussen RA, Alentorn-Geli E, et al. Equivalent knee injury and osteoarthritis outcome scores 12 and 24 months after anterior cruciate ligament reconstruction: Results from the Swedish National Knee Ligament Register. Am J Sports Med 2017;45:2085-2091.

29. Hamrin-Senorski E, Sundemo DS, Murawski CD, et al. No differences in the improvement of subjective knee function between surgical techniques of single-bundle anterior cruciate ligament reconstruction at two years followup-A cohort study from the swedish national knee ligament register. Arthroscopy 2017;33:e98-e99 (10 Suppl 1).

30. Nissen KA, Eysturoy NH, Nielsen TG. Allograft use results in higher re-revision rate for revision anterior cruciate ligament reconstruction. Orthop J Sport Med 2018;6(6): 2325967118775381.

31. Lind M, Nielsen TG, Behrndtz K. Both isolated and multiligament posterior cruciate ligament reconstruction results in improved subjective outcome: results from the Danish Knee Ligament Reconstruction Registry. Knee Surg Sports Traumatol Arthrosc 2018;26:1190-1196.

32. Fauno P, Rahr-Wagner L. Risk for revision after anterior cruciate ligament reconstruction is higher among adolescents: Results from the Danish registry of knee ligament reconstruction. Orthop J Sport Med 2014;2(10):1-7.

33. Rahr-Wagner L, Thillemann TM, Pedersen AB. Comparison of hamstring tendon and patellar tendon grafts in anterior cruciate ligament reconstruction in a nationwide population-based cohort study: Results from the danish registry of knee ligament reconstruction. Am J Sports Med 2014;42:278-284.

34. Rahr-Wagner L, Thillemann TM, Pedersen AB. Increased risk of acl revision after anteromedial compared to transtibial technique for femoral drillhole placement during ACL reconstruction. result from the danish registry of knee ligament reconstruction. Arthroscopy 2013;29:e79 (10 Suppl. 1).

35. Sandon A, Engstrom B, Forssblad M. High risk of further anterior cruciate ligament injury in a 10-year follow-up study of anterior cruciate ligament-reconstructed soccer players in the Swedish National Knee Ligament Registry. Arthroscopy 2020;36:189-195.

36. Kraus-Schmitz J, Lindgren V, Janarv P-M, Forssblad M. Deep venous thrombosis and pulmonary embolism after anterior cruciate ligament reconstruction. Bone Jt $J$ 2019;101B(1):34-40.

37. Hamrin Senorski E, Alentorn-Geli E, Musahl V, et al. Increased odds of patient-reported success at 2 years after anterior cruciate ligament reconstruction in patients without cartilage lesions: A cohort study from the Swedish National Knee Ligament Register. Knee Surg Sports Traumatol Arthrosc 2018;26:1086-1095.

38. Holleyman R, Sohatee MA, Witt J, et al. Periacetabular osteotomy for developmental dysplasia of the hip and femoroacetabular impingement: A study using the U.K. Non-Arthroplasty Hip Registry (NAHR) Data Set. J Bone Joint Surg Am 2020;102:1312-1320.

39. Rahr-Wagner L, Thillemann TM, Pedersen AB, Lind MC. Increased risk of revision after anteromedial compared with transtibial drilling of the femoral tunnel during primary anterior cruciate ligament reconstruction: Results from the danish knee ligament reconstruction register. Arthroscopy 2013;29:98-105.

40. Bjerre JJ, Jensen PK, Sparso BH. Potential serious bias in National Clinical Databases with low degree of reported follow-up. Scand J Med Sci Sports 2017;27: 999-1004.

41. Ageberg E, Forssblad M, Herbertsson P. Sex differences in patient-reported outcomes after anterior cruciate ligament reconstruction: data from the Swedish knee ligament register. Am J Sports Med 2010;38:1334-1342.

42. Hamrin Senorski E, Svantesson E, Beischer S, et al. Factors affecting the achievement of a patient-acceptable symptom state 1 year after anterior cruciate ligament reconstruction: A cohort study of 343 patients from 2 registries. Orthop J Sport Med 2018;6(4): 2325967118764317.

43. Grindem H, Granan LP, Risberg MA, Engebretsen L, Snyder-Mackler L. How does a combined preoperative and postoperative rehabilitation programme influence the outcome of ACL reconstruction 2 years after surgery? A comparison between patients in the Delaware-Oslo ACL Cohort and the Norwegian National Knee Ligament Registry. Br J Sports Med 2015;49:385-389.

44. Barenius B, Forssblad M, Engstrom B. Functional recovery after anterior cruciate ligament reconstruction, a study of health-related quality of life based on the Swedish National Knee Ligament Register. Knee Surg Sport Traumatol Arthrosc 2013;21:914-927.

45. Ahlden M, Samuelsson K, Sernert N, Forssblad M, Karlsson J. The Swedish National Anterior Cruciate Ligament Register: A report on baseline variables and outcomes of surgery for almost 18,000 patients. Am J Sports Med 2012;40:2230-2235. 
46. Thabane L, Mbuagbaw L, Zhang S, et al. A tutorial on sensitivity analyses in clinical trials: The what, why, when and how. BMC Med Res Methodol 2013;13:92.

47. Kunze KN, Burnett RA, Lee EK, Rasio JP, Nho SJ. Development of Machine Learning Algorithms to Predict Being Lost to Follow-up After Hip Arthroscopy for Femoroacetabular Impingement Syndrome. Arthrosc Sport Med Rehabil 2020;2(5):e591-e598.

48. Ekholm O, Gundgaard J, Rasmussen NKR, Hansen EH. The effect of health, socio-economic position, and mode of data collection on non-response in health interview surveys. Scand J Public Health 2010;38:699-706.

49. Lindman I, Olsson H, Öhlin A, et al. Loss to follow-up: Initial non-responders do not differ from responders in terms of 2-year outcome in a hip arthroscopy registry. J Hip Preserv Surg 2020;7:281-287.

50. Juto H, Gärtner Nilsson M, Möller M, Wennergren D, Morberg P. Evaluating non-responders of a survey in the Swedish fracture register: no indication of different functional result. BMC Musculoskelet Disord $2017 ; 18: 278$.

51. Højmark K, Støttrup C, Carreon L, Andersen MO. Patientreported outcome measures unbiased by loss of follow-up. Single-center study based on DaneSpine, the Danish spine surgery registry. Eur Spine J 2016;25:282-286.

52. Kwon SK, Kang YG, Chang CB, Sung SC, Kim TK. Interpretations of the clinical outcomes of the nonresponders to mail surveys in patients after total knee arthroplasty. J Arthroplasty 2010;25:133-137.

53. Kim J, Lonner JH, Nelson CL, Lotke PA. Response bias: Effect on outcomes evaluation by mail surveys after total knee arthroplasty. J Bone Joint Surg Am 2004;86:15-21.

54. The Swedish knee ligament registry. The Swedish knee ligament registry. Annual Report 2019:2018:3.

55. Roos EM, Roos HP, Lohmander LS, Ekdahl C, Beynnon BD. Knee Injury and Osteoarthritis Outcome Score (KOOS)-Development of a self-administered outcome measure. J Orthop Sport Phys Ther 1998;28(2). doi:10.2519/jospt.1998.28.2.88.

56. Griffin DR, Parsons N, Mohtadi NGH, Safran MR. A short version of the International Hip Outcome Tool (iHOT-12) for use in routine clinical practice. Arthrosc J Arthrosc Relat Surg 2012;28:611-616. quiz 616-618.

57. Treuting R. Minimally invasive orthopedic surgery: Arthroscopy. Ochsner J 2000;2(3):158.

58. Hamrin Senorski E, Svantesson E, Beischer S, Thomee C, Thomee R, Karlsson J. Low l-year return-to-sport rate after anterior cruciate ligament reconstruction regardless of patient and surgical factors: A prospective cohort study of 272 patients. Am J Sports Med 2018;46:1551-1558.

59. Hamrin Senorski E, Svantesson E, Beischer S, et al. Concomitant injuries may not reduce the likelihood of achieving symmetrical muscle function one year after anterior cruciate ligament reconstruction: A prospective observational study based on 263 patients. Knee Surg Sports Traumatol Arthrosc 2018;26:2966-2977.

60. Owesen C, Sivertsen EA, Engebretsen L, Granan LP. Patients with isolated PCL injuries improve from surgery as much as patients with ACL injuries after 2 years. Orthop $J$ Sport Med 2015;3(8):2325967115599539.

61. Lund B, Kraemer O, Holmich P, Maagaard N, Winge S, Mygind-Klavsen B. The Danish Hip Arthroscopy Registry (DHAR). Annual Report 2019:1-26:2019.

62. Non Arthroplasty Hip Registry. Non-Arthroplasty Hip Registry: 5th Annual Report 2020, http://www.fas.org.sg/ wp-content/uploads/2020/09/FAS-Annual-Report-Apr2019-Mar-2020.pdf 2020.

63. Rahardja R, Zhu M, Love H, Clatworthy MG, Monk AP, Young SW. New Zealand ACL Registry Annual Report 2019. 2019:1-16.

64. Gabr A, De Medici A, Haddad F. The National Ligament Registry The Sixth Annual Report (2020). 2020.

65. Bergen H. Report June 2020-Norwegian National Advisory Unit of Arthroplasty and Hip Fractures. 2020;8906.

66. Aagaard H, Bertelsen S, Hjelm A, et al. Dansk Korsbånds Rekonstruktions $\quad$ Register-Årsrapport 2019. 2019; (December 2018):1-83.

67. Maurer J, Grotejohann B, Jenkner C, et al. A registry for evaluation of efficiency and safety of surgical treatment of cartilage defects: the German Cartilage Registry (Knorpel Register DGOU). JMIR Res Protoc 2016;5(2):e122. 
Supplementary Table S1. Table Outlining Search Times Used on MEDLINE and EMBASE to Find Studies From Each of the Included Registries

\begin{tabular}{lll}
\hline Registry & \multicolumn{1}{c}{ Search Terms } & Annual Report Year \\
\hline DART & German Arthroscopy regist* OR German Registr* of Arthroscopy OR Deutschsprachiges Arthroskopieregister & Not found \\
DGOU & German Cartilage Regist* OR KnorpelRegister DGOU OR DGOU Cartilage Regist* & 2017 \\
NZACLR & New Zealand Anterior Cruciate Ligament Regist* OR New Zealand ACL Regist* OR NZACL OR NZACLR & 2020 \\
DHAR & Danish Hip Arthroscopy Regist* & 2019 \\
DKRR & Danish Knee Ligament Reconstruction Regist* OR DKRR OR Danish Cruciate Ligament Regist* OR DKKR & 2019 \\
NKLR & Norwegian Cruciate Ligament Regist* OR Norwegian Knee Ligament Regist* OR NKLR & 2020 \\
NLR & National Ligament Regist* & \\
NAHR & Non-arthroplasty hip regist* & 2020 \\
SNKLR & Swedish National Knee Ligament Regist* OR Swedish Knee Ligament Regist* OR Swedish Anterior & 2020 \\
& $\quad$ Cruciate Ligament Regist* OR Swedish National Anterior Cruciate Ligament Regist* OR SNKLR OR SKLR & 2019
\end{tabular}

DART, German Arthroscopy Registry; DGOU, German Cartilage Registry; NZACLR, New Zealand ACL Registry; DHAR, Danish Hip Arthroscopy Registry; DKRR, Danish Knee Ligament Reconstruction Registry; NKLR, Norwegian Knee Ligament Registry; NLR, United Kingdom National Ligament Registry; NAHR, United Kingdom Non-Arthroplasty Hip Registry; SNKLR, Swedish National Knee Ligament Registry.

Articles included in each of the latest annual reports of the registries were also screened for studies. Annual Reports were searched for online on the website of each respective registry. ${ }^{54,61-67}$ 
Supplementary Table S2. Summary of the Included Registries From Which Studies Were Selected

\begin{tabular}{|c|c|c|c|c|c|c|c|}
\hline Registry & $\begin{array}{l}\text { Information } \\
\text { Collected from }\end{array}$ & $\begin{array}{l}\text { Year data Collection } \\
\text { Initiated from }\end{array}$ & Entries & PROMs & $\begin{array}{l}\text { Collection Time Points } \\
\text { (years) }\end{array}$ & $\begin{array}{c}\text { Registry } \\
\text { Compliance Pre-op } \\
\end{array}$ & $\begin{array}{c}\text { Registry Compliance } \\
\text { Post-op }\end{array}$ \\
\hline DGOU & 2017 Annual Report ${ }^{*}$ & & 5339 & & & & \\
\hline NZACLR & 2019 Annual Report & 2014 & 9849 & Marx, KOOS & $0.5,1,2,5$ & & $\begin{array}{l}6 \text { months: }>75 \% \\
12 \text { months: }>70 \% \\
24 \text { months }>70 \% \\
60 \text { months: }>50 \%\end{array}$ \\
\hline $\begin{array}{l}\text { Danish Hip Arthroscopy } \\
\text { Registry (DHAR) }\end{array}$ & 2019 Annual Report & 2012 & 6214 & $\begin{array}{l}\text { HAGOS, iHOT-12, } \\
\text { HSAS, VAS- hip } \\
\text { function, NRS-rest, } \\
\text { NRS-walk, EQ5D }\end{array}$ & $1,2,5,10$ & Pre-op: $57 \%$ & $\begin{array}{l}1 \text { year: } 59 \% \\
2 \text { year: } 51 \% \\
5 \text { year: } 45 \%\end{array}$ \\
\hline $\begin{array}{l}\text { Danish Knee Ligament } \\
\text { Reconstruction } \\
\text { Registry (DKRR) }\end{array}$ & 2019 Annual Report $^{\dagger}$ & 2005 & 35946 & KOOS, Tegner Activity & 1 & $40 \%$ & $35 \%$ \\
\hline $\begin{array}{l}\text { Norwegian Knee } \\
\text { Ligament Registry } \\
\text { (NKLR) }\end{array}$ & 2020 Annual Report & 2004 & 31975 & KOOS & $2,5,10$ & & $\begin{array}{c}2 \text { year: } 60.6 \% \\
5 \text { year: } 56.7 \% \\
10 \text { year: } 56.6 \%\end{array}$ \\
\hline $\begin{array}{l}\text { United Kingdom } \\
\text { National Ligament } \\
\text { Registry (NLR) }\end{array}$ & 2019 Annual Report & 2013 & 12558 & $\begin{array}{l}\text { EQ5D, Tegner Activity, } \\
\text { IKDC, KOOS }\end{array}$ & $0.5,1,2$ & $58 \%$ & $\begin{array}{l}1 \text { year: } 37 \% \\
2 \text { year: } 32 \%\end{array}$ \\
\hline $\begin{array}{l}\text { United Kingdom Non- } \\
\text { Arthroplasty Hip } \\
\text { Registry (NAHR) }\end{array}$ & 2020 Annual Report & 2012 & 12992 & $\begin{array}{l}\text { EQ5D, EQVAS, iHOT- } \\
12\end{array}$ & $0.5,1,2$ & & \\
\hline $\begin{array}{l}\text { Swedish National Knee } \\
\text { Ligament Registry } \\
\text { (SNKLR) }\end{array}$ & 2019 Annual Report & 2005 & 52816 & EQ5D, EQVAS, KOOS & $1,2,5,10$ & $67 \%$ & $\begin{array}{c}1 \text { year: } 55 \% \\
2 \text { year: } 49 \% \\
5 \text { year: } 45 \% \\
10 \text { year: } 38 \% \text { (EQ5D) }\end{array}$ \\
\hline
\end{tabular}

Pre-op, before surgery; Post-op, after surgery; DART, German Arthroscopy Registry; DGOU, German Cartilage Registry; NZACLR, New Zealand ACL Registry; DHAR, Danish Hip Arthroscopy Registry; DKRR, Danish Knee Ligament Reconstruction Registry; NKLR, Norwegian Knee Ligament Registry; NLR, United Kingdom National Ligament Registry; NAHR, United Kingdom NonArthroplasty Hip Registry; SNKLR, Swedish National Knee Ligament Registry; PROM, patient reported outcome measures; KOOS, Knee Injury and Osteoarthritis Outcome Score; HAGOS, Copenhagen Hip and Groin Outcome Score; iHOT-12, International Hip Outcome Tool; HSAS, Hip Sports Activity Scale; VAS, visual analog scale; NRS, Numerical Rating Scale; EQ5D, EuroQol Outcome Measure; IKDC, International Knee Documentation Committee Score; EQVAS, EuroQol Visual Analogue Scales.

Data were collected from the websites and the latest annual reports of each registry. ${ }^{54,61-67}$ If no overall compliance is given, but multiple compliances are given for each individual PROM, the

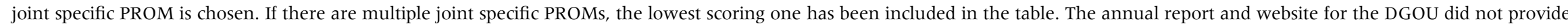

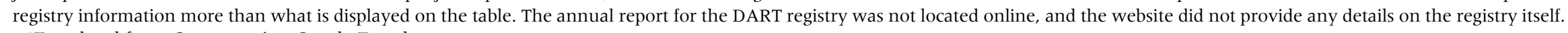
*Translated from German using Google Translate.

${ }^{\dagger}$ Translated from Danish using Google Translate. 